\title{
Lung Ultrasound for diagnosis of acute cardiogenic dyspnea in the Emergency Department - a simeu multicenter study
}

\author{
E Pivetta ${ }^{1,2,3,4^{*}}$, M Tizzani $^{5}$, G Porrino ${ }^{5}$, E Ferreri ${ }^{5}, G$ Volpicelli ${ }^{7}$, P Balzaretti ${ }^{8}$, A Banderali ${ }^{6}$, A lacobucci ${ }^{9}$, S Locatelli ${ }^{4,6}$, \\ F Merletti ${ }^{1}$, I Baldi ${ }^{1,10}$, G Casoli $^{11}$, E Lupia ${ }^{4}$, GA Cibinel ${ }^{2}$ \\ From 7th WINFOCUS Italian Congress on Ultrasound in Emergency, Anaesthesiology and Critical Care \\ Lodi, Italy. 26-29 March 2014
}

\section{Introduction}

Acute dyspnea is among the most common presentations to the Emergency Department (ED). Discriminating between cardiac and non-cardiac causes of dyspnea can sometimes be challenging. Lung Ultrasound (LUS), integrated with standard clinical evaluation (i.e. history, physical examination, EKG and arterial blood gas - iLUS) has emerged as a non-invasive bedside valuable technique for diagnosis of various diseases.

\section{Objectives}

Aim of this study was to evaluate diagnostic accuracy of iLUS in identifying cardiac causes of shortness of breath in the ED.

\section{Patients and methods}

This is a multicentric prospective cohort, involving seven Italian EDs (AOU Città della Salute e della Scienza di Torino, "E. Agnelli" General Hospital - Pinerolo, AO Ordine Mauriziano, Turin, Martini Hospital, Turin, AOU San Luigi Gonzaga, Orbassano, Cardinal Massaia Hospital, Asti, and ASO Santa Croce e Carle, Cuneo, all in Piedmont). Neither traumatic nor already invasively ventilated patients presenting to the ED with a principal complaint of shortness of breath were elegible. After initial clinical assessment, emergency physician is asked to indicate the main diagnosis (cardiac or respiratory dyspnea). Then LUS scanning is performed by the same emergency physician and, at this point, a new presumptive diagnosis (iLUS), based on both initial clinical

\footnotetext{
* Correspondence: emanuele.pivetta@gmail.com

${ }^{1}$ Unita di Epidemiologia dei Tumori e CPO Piemonte, Dipartimento di

Scienze Medihe, CeRMS e Universita di Torino, Torino, Italy

Full list of author information is available at the end of the article
}

assessment and LUS findings, is recorded. All patients also underwent standard chest radiography (CXR). After discharge, the entire medical records are independently reviewed by two emergency physicians blinded to the LUS results, in order to determine the final diagnosis of patient's dyspnea (in case of disagreement, a third emergency physician determined final diagnosis).

\section{Results}

1005 patients were enrolled among October 2010 and September 2012. The median age was 77 years (range 18-100 years) and M/F ratio was 1.16 . Clinical evalutation had a sensitivity of $85.3 \%$ (95\% CI 81.8-88.4) and a specificity of $90 \%$ (95\% CI 87.2-92.4) for the diagnosis of cardiogenic dyspnea. "iLUS" had a sensitivity of $97 \%$ (95\% CI 95-98.3) and a specificity of $97.4 \%$ (95\% CI 95.7-98.6). CXR had a sensitivity of $69.5 \%$ (95\% CI 65.1 73.7) and a specificity of $82.1 \%$ (95\% CI 78.6-85.2).

\section{Conclusions}

Results of our study showed a high iLUS diagnostic accuracy for the diagnosis of cardiogenic dyspnea among patients admitted to the ED, higher than clinical assessment, and CXR.

\footnotetext{
Authors' details

'Unita di Epidemiologia dei Tumori e CPO Piemonte, Dipartimento di Scienze Medihe, CeRMS e Universita di Torino, Torino, Italy. ${ }^{2}$ Medicina e Chirurgia d'accettazione e d'urgenza, Ospedale "E. Agnelli", Pinerolo, Torino, Italy. '3epartment of Emergency Medicine, Brigham and Women's Hospital, MA, USA. ${ }^{4}$ Medicina d'Urgenza, A.O.U. Citta della salute e della Scienza, e Universita di Torino, Torino, Italy. ${ }^{5}$ Medicina d'Urgenza, A.O.U. Citta della salute e della Scienza, Torino, Italy. ${ }^{6}$ Pronto Soccorso, Ospedale "Cardinal Massaia", Asti, Italy. 'Medicina d'Urgenza, A.O.U. San Luigi Gonzaga, Orbassano, Torino, Italy. "Medicina d'Urgenza, Ospedale "Ordine Mauriziano", Torino, Italy. ${ }^{9}$ Medicina d'Urgenza, A.O. Santa Croce e Carle, Cuneo, Italy.
} 
doi:10.1186/2036-7902-6-S2-A5

Cite this article as: Pivetta et al: Lung Ultrasound for diagnosis of acute cardiogenic dyspnea in the Emergency Department - a simeu multicenter study. Critical Ultrasound Journal 2014 6(Suppl 2):A5.

\section{Submit your manuscript to a SpringerOpen ${ }^{\mathcal{O}}$ journal and benefit from:}

- Convenient online submission

- Rigorous peer review

- Immediate publication on acceptance

- Open access: articles freely available online

- High visibility within the field

- Retaining the copyright to your article

Submit your next manuscript at $\gg$ springeropen.com 